\title{
Primary or metastatic hepatic carcinoma? A breast cancer patient after adjuvant chemotherapy and radiotherapy postoperatively with intrahepatic cholangiocarcinoma and review of the literature
}

Zhao-yun Liu' ${ }^{1,2+}$, Ju-jie Sun ${ }^{2 \dagger}$, Ke-wen He ${ }^{1,2}$, Pei-ying Zhuo ${ }^{2}$ and Zhi-yong Yu ${ }^{2 *}$

\begin{abstract}
Background: The liver is a common site of metastases, followed by the bone and lung in breast cancer. The symptoms of hepatic metastases are similar to intrahepatic cholangiocarcinoma (ICC). ICC is rare, with an overall incidence rate of 0.95 cases per 100,000 adults. The incidence of ICC for patients with breast cancer is very uncommon. Breast cancer patient with ICC is easily misdiagnosed as hepatic metastases.

Case presentation: We report a breast cancer patient postoperatively who was hospitalized because of having continuous irregular fever for 1 month. Antibiotics were given for 1 week without any significant effect. Her admission bloods revealed elevated levels of carcino-embryonic antigen. Magnetic resonance imaging diagnosis showed multiple liver metastases. We believed that the woman had hepatic metastases until biopsy guided by computed tomography. The liver biopsy pathology analysis considered the possibility of primary intrahepatic cholangiocarcinoma.

Conclusions: Breast cancer patient with space-occupying lesions in the liver is easily considered to be progressed hepatic metastases. Image-guided biopsy is the best diagnostic method for breast cancer with liver mass to avoid misdiagnosis and classify the molecular subtypes to make appropriate treatment.
\end{abstract}

Keywords: Breast neoplasm, Liver metastases, Intrahepatic cholangiocarcinoma

\section{Background}

Intrahepatic cholangiocarcinoma (ICC) is a rare tumor, accounting for $3 \%$ of all gastrointestinal malignancies worldwide [1-4]. With similar signs and symptoms to metastatic hepatic carcinoma including right abdominal pain, low-grade fever, nausea, anorexia, weight loss, and jaundice, ICC lacks typical clinical manifestations and is hard to differentiate from liver metastases using imaging

\footnotetext{
* Correspondence: drzhiyongyu@aliyun.com

${ }^{\dagger}$ Equal contributors

2Department of Oncology, Shandong Academy of Medical Sciences,

Shandong Cancer Hospital affiliated to Shandong University, 440 Ji-Yan Road,

Jinan 250117, Shandong Province, People's Republic of China

Full list of author information is available at the end of the article
}

modalities and tumor markers. For breast cancer, the liver metastatic is common [5, 6]. Approximately, in $10 \%$ of the cases, distant metastases are already present at the time of diagnosis, and it is considered that more than $50 \%$ of the patients with advanced breast cancer will develop hepatic metastasis at some point [7-9]. The main treatment to breast cancer with hepatic metastasis is systemic chemotherapy; however, curative resections are the only currently well-established option for ICC. Pathologic diagnosis is important to breast cancer patient with space-occupying lesions of the liver in order to avoid misdiagnosis and mistherapy. In the case 

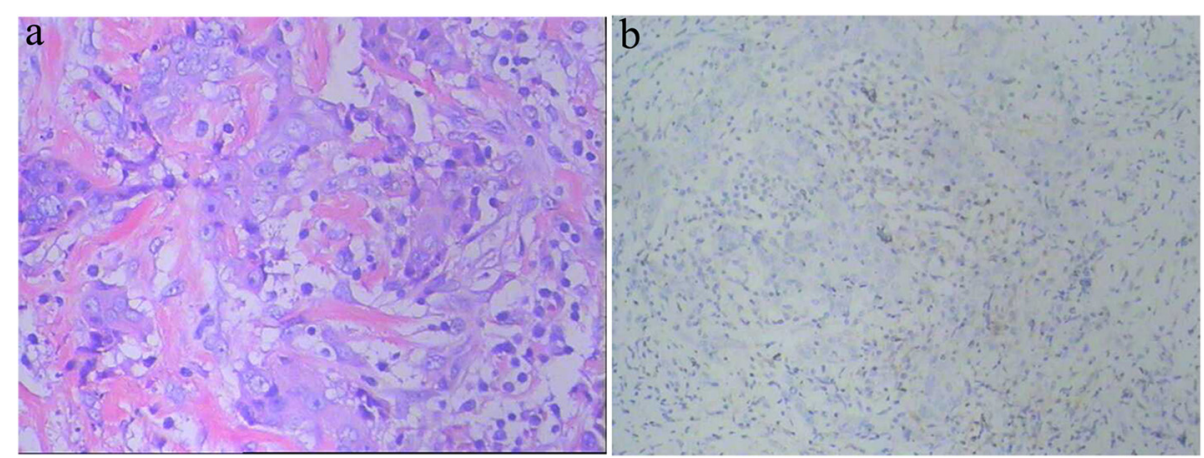

Fig. 1 Photomicrographs of invasive breast carcinoma. a Light microscopy sections with hematoxylin and eosin staining demonstrating markedly atypical endothelial cells $(H E, \times 200)$. b The chief cells showed positive staining to CD10 (IHC, ×100)

presented here, we report a breast cancer patient postoperatively diagnosed with ICC other than hepatic metastases.

\section{Case presentation}

A 48-year-old woman with "left breast cancer" was hospitalized in Shandong Cancer Hospital \& Institute. This patient underwent modified radical mastectomy on July 18, 2014. Pathology diagnosis (Fig. 1): invasive ductal carcinoma, maximum diameter of the mass is $1.3 \mathrm{~cm}$. Axillary lymph nodes involved level I $3 / 20$, level II $0 / 20$, and level III $0 / 1$. The pathological staging was $\mathrm{T}_{1} \mathrm{~N}_{1} \mathrm{M}_{0}$, stage IIA, which predicts the locally advanced disease. Immunohistochemistry results are the following: ER (-), PR (-), CerbB-2 positive (3+), and Ki-67+ (20\%). The patient refused targeted trastuzumab therapy because of personal economic situation. Chemotherapy regimen including AC (pirarubicin, $80 \mathrm{mg}, \mathrm{d}_{1}$; cyclophosphamide, $0.8 \mathrm{~g}, \mathrm{~d}_{1}$ ) sequential TP (docetaxel, $120 \mathrm{mg} \mathrm{d} \mathrm{d}_{1}$; cisplatinum, $60 \mathrm{mg} \mathrm{d}, \mathrm{d}_{2}$ ) was implemented after operation. Next, local radiotherapy was implemented on the left side of the chest wall and the left clavicle lymph drainage area, DT 50 Gy/25 times.

Fourteen months later, this patient was again hospitalized on Sep.19, 2015, because of having continuous irregular fever for 1 month. Antibiotics were given for 1 week without any significant effect observed. We excluded the possibility of common infectious diseases. Computed tomography (CT) revealed low-density foci in the right liver lobe. The carcino-embryonic antigen (CEA) was $7.29 \mathrm{ng} / \mathrm{mL}$, while the standard value is less than $3.4 \mathrm{ng} / \mathrm{mL}$. We suspected the women had liver metastasis after breast cancer surgery, and the magnetic resonance imaging (MRI) abdomen diagnosis on Sep.20, 2015, was consistent with what we had suspected (Fig. 2). Neither cerebral MRI nor whole body bone scan revealed obvious abnormity or other distant metastases. However, on Sep.23, 2015, pathology analysis through row CT-guided liver biopsy demonstrated for poorly differentiated adenocarcinoma. Furthermore, the photomicrographs (Fig. 3) including eosin staining (HE), CK7, and CK19 accord with the characteristics of the low differentiation of intrahepatic bile duct carcinoma (ICC), which is the primary intrahepatic lesions.

\section{Discussion}

Breast cancer, the most common malignant cancer in women worldwide, is a main cause of cancer death in females and the second in the general population just after lung cancer. Liver metastases have a 5-year survival rate
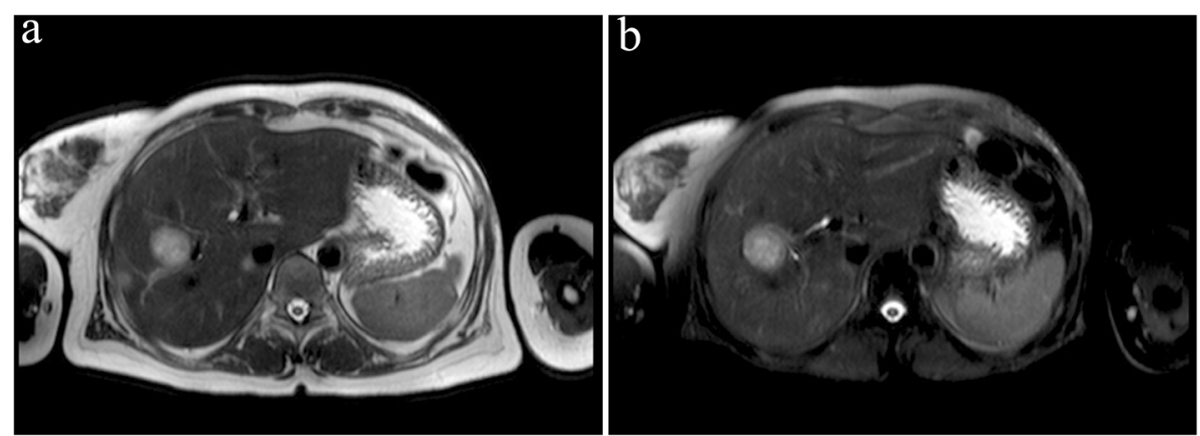

Fig. 2 Liver magnetic resonance image (MRI) after the patient have continued irregular fever for 1 month 


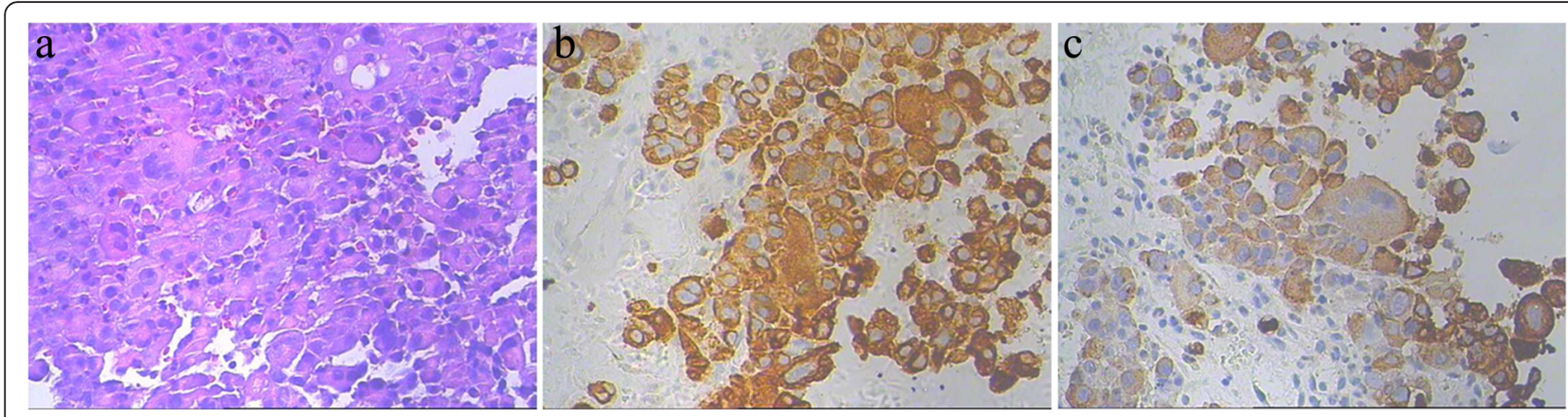

Fig. 3 Photomicrographs of intrahepatic cholangiocarcinoma. a Eosin staining demonstrating markedly atypical cells (HE $\times 200)$. b CK7,cytoplasm $+($ IHC, $\times 200) \cdot \mathbf{c}$ CK19, cytoplasm + (IHC, ×200)

of 0 to $12 \%$, which is the poorest prognosis of all types of breast cancer metastases [10]. Metastases seed the liver via systemic circulation with a microscopic dissemination and may be present in multiple sites [11-13]. Considering this patient with lymph node metastasis and positive CerbB-2 expression, she was suspected of getting liver metastases first, and the MRI imaging approved this hypothesis. Symptoms such as abdominal fullness, back pain, fatigue, nausea, anorexia, low-grade fever, and weight loss usually occur during the progression of liver metastasis. In this case, we hypothesize that the fever of the woman may result from tumor tissue necrosis, infection, and tumor metabolites. The vast majority of patients with liver metastasis from breast cancer also have metastasis in other parts of their bodies. Thus, systemic treatment served as a better choice. Due to the limitation of operation range, surgical practice in patients with liver metastasis from breast cancer is still under debate. The majority of clinicians do not support surgery with the role of surgery being strictly limited for palliation of metastatic complications or locoregional relapse, while others supported this method for its costeffectiveness with superior 5-year survival for selected patients with isolated liver metastases and in those with well-controlled minimal extrahepatic disease [14, 15].

ICC is one of the primary malignant liver tumors with a prevalence of 5-20\% in hepatic carcinoma cases [16]. Although patients with ICC exhibited hepatic region pain, weight loss, or few of irregular fever, a considerable number of patients are asymptomatic $[17,18]$. The patient in our report had fever as the first symptom is easily misdiagnosed. The nonspecific tumor markers CEA can be found elevated both in ICC and in liver metastasis. It is not helpful for us to do a differential diagnosis with this woman who only had CEA elevated [17]. Imaging features of ICC are space-occupying lesions in the liver [19], which we are easily confused with liver metastases. Due to the challenges in their detection and treatment, ICC is usually already progressed invasively and transfers to the lymphatic system during its early stage $[20,21]$. Though the resectability and curability remain low compared to other hepatobiliary tumors, surgical resection is the preferred treatment for the ICC [22].

This breast cancer patient 1 year after surgery has continuous irregular fever for 1 month, and 1-week intravenous antibiotics were of no use. With the MRI imaging findings and elevated levels of CEA, as well as the unstandardized treatment of HER2 target, we easily believed that this breast cancer patient had hepatic metastases. But the liver biopsy pathology analysis by CT-guided biopsy led us to consider the possibility of primary ICC.

\section{Conclusions}

This breast cancer patient postoperatively was diagnosed to hepatic metastases with the clinical symptoms and imaging diagnosis until the biopsy results were reported to primary ICC. For breast cancer patients with liver space-occupying lesions, we should not treat them imprudently to the liver metastasis of breast cancer. Instead, we should make careful judgment bases on the biopsy and pathology diagnosis, providing the basis for subsequent treatment. Imaging-guided biopsy should be chosen to breast cancer patient with space-occupying lesions of the liver in order to avoid misdiagnosis and classify the molecular subtypes to make appropriate treatment.

\section{Abbreviations \\ CEA, carcino-embryonic antigen; CT, computed tomography; ICC, intrahepatic cholangiocarcinoma; MRI, magnetic resonance imaging}

\section{Acknowledgements}

We are thankful to the patient for her cooperation which was of utmost importance in the study.

\section{Funding}

No specific funding was received for this work.

\section{Availability of data and materials}

The authors do not wish to share their data; they respect the patient's rights to privacy and to protect his identity. The authors presented, in the

manuscript, all the necessary information about their case report. Raw data regarding our patient is in his admission file, a file that is strictly confidential, without the possibility of publishing raw data from it. 


\section{Authors' contributions}

L-ZY and S-JJ reviewed the literature and wrote the initial draft. H-KW and Z-PY helped collect the clinical information. Y-ZY designed the study. All authors have read and approved the final manuscript.

\section{Competing interests}

The authors declare that they have no competing interests.

\section{Consent for publication}

Written informed consent was obtained from the patients for publication of these case reports and any accompanying images. Copies of the written consent are available for review by the Editor-in-Chief of this journal.

\section{Ethics approval}

This study was approved by the ethical review committee of Shandong

Cancer Hospital \& Institute, and the committee's reference number is 201602004.

\section{Author details}

'School of Medicine and Life Sciences, University of Jinan-Shandong Academy of Medical Sciences, Jinan, Shandong, People's Republic of China. ${ }^{2}$ Department of Oncology, Shandong Academy of Medical Sciences, Shandong Cancer Hospital affiliated to Shandong University, 440 Ji-Yan Road, Jinan 250117, Shandong Province, People's Republic of China.

Received: 1 March 2016 Accepted: 8 July 2016

Published online: 15 July 2016

\section{References}

1. Yizhou W, Jun L, Yong X, Renyan G, Kui W, Zhenlin Y, Xuying W, Guanghua L, Dong W, Lehua S. Prognostic nomogram for intrahepatic cholangiocarcinoma after partial hepatectomy. J Clin Oncol Off J Am Soc Clin Oncol. 2013;31:1188-95.

2. Maithel SK, Gamblin TC, Ihab K, Celia Pamela CV, Melanie T, Pawlik TM Multidisciplinary approaches to intrahepatic cholangiocarcinoma. Cancer. 2013:119:3929-42.

3. Lafaro KJ, Cosgrove D, Geschwind JFH, Kamel I, Herman JM, Pawlik TM. Multidisciplinary care of patients with intrahepatic cholangiocarcinoma: updates in management. Gastroenterol Res Pract. 2015;2015:1-14.

4. Li H, Hu B, Zhou ZQ, Guan J, Zhang ZY, Zhou GW. Hepatitis C virus infection and the risk of intrahepatic cholangiocarcinoma and extrahepatic cholangiocarcinoma: evidence from a systematic review and meta-analysis of 16 case-control studies. World J Surg Oncol. 2015:13:161-8.

5. Largillier R, Ferrero JM, Doyen J, Barriere J, Namer M, Mari V, Courdi A, Hannoun-Levi JM, Ettore F, Birtwisle-Peyrottes I, et al. Prognostic factors in 1,038 women with metastatic breast cancer. Ann Oncol. 2008;19:2012-9.

6. Atalay G, Biganzoli L, Renard F, Paridaens R, Cufer T, Coleman R, Calvert AH, Gamucci T, Minisini A, Therasse P, et al. Clinical outcome of breast cancer patients with liver metastases alone in the anthracycline-taxane era: a retrospective analysis of two prospective, randomised metastatic breast cancer trials. Eur J Cancer. 2003;39:2439-49.

7. Lin NU, Christoph T, Fatima C, David C, Tanja C, Lesley F, Francis PA, Stella K, Olivia P, Elzbieta S. International guidelines for management of metastatic breast cancer (MBC) from the European School of Oncology (ESO)-MBC Task Force: surveillance, staging, and evaluation of patients with early-stage and metastatic breast cancer. Breast. 2013:22:203-10.

8. Bochicchio A, Tartarone A, Ignomirelli O, Latorre G, Cangiano R, Gallucci G, Coccaro M. Feudale E, Aieta M. Anal metastasis from breast cancer: a case report and review of the literature. Future Oncol. 2012;8:333-6.

9. Mano MS, Cassidy J, Canney P. Liver metastases from breast cancer: management of patients with significant liver dysfunction. Cancer Treat Rev. 2005:31:35-48.

10. Ruiz A, Wicherts D, Adam R, Siesling S, Linn S, Hillegersberg R. Resection of liver metastases in breast cancer. Ned Tijdschr Geneeskd. 2015;159:A8453.

11. Hsu KC, Li TY, Chu HY, Chen LC, Chang ST, Wu YT. Conus medullaris metastasis in breast cancer: report of a case and a review of the literature. Surg Today. 2013:43:910-4

12. Qu Q, Zong Y, Fei XC, Chen XS, Xu C, Lou GY, Shen KW. The importance of biopsy in clinically diagnosed metastatic lesions in patients with breast cancer. World J Surg Oncol. 2014;12:1-6.
13. Gong HY, Hu WG, Hu QY, Li XP, Song QB. Radiation-induced pulmonary injury accelerated pulmonary metastasis in a mouse model of breast cancer. Oncol Lett. 2015;10:3613-8.

14. Sadot E, Lee SY, Sofocleous CT, Solomon SB, Gonen M, Peter Kingham T, Allen PJ, DeMatteo RP, Jarnagin WR, Hudis CA, D'Angelica MI. Hepatic resection or ablation for isolated breast cancer liver metastasis: a casecontrol study with comparison to medically treated patients. Ann Surg. 2016;264:147-54.

15. Bacalbasa N, Dima SO, Purtan-Purnichescu R, Herlea V, Popescu I. Role of surgical treatment in breast cancer liver metastases: a single center experience. Anticancer Res. 2014:34:5563-8.

16. Khan SA, Toledano MB, Taylor-Robinson SD. Epidemiology, risk factors, and pathogenesis of cholangiocarcinoma. HPB. 2008;10:77-82.

17. Dodson RM, Weiss MJ, Cosgrove D, Herman JM, Kamel I, Anders R, Geschwind JFH, Pawlik TM. Intrahepatic cholangiocarcinoma: management options and emerging therapies. J Am Coll Surg. 2013;217:736-50.

18. Martina C, Roberto M, Mirco P, Paolo V, Federico M, Marco V. Metastatic breast cancer mimicking a hilar cholangiocarcinoma: case report and review of the literature. World J Surg Oncol. 2014;12:384.

19. Ringe Kl, Wacker F. Radiological diagnosis in cholangiocarcinoma: application of computed tomography, magnetic resonance imaging, and positron emission tomography. Best Pract Res Clin Gastroenterol. 2015;29:253-65.

20. Zhang H, Yang T, Wu M, Shen F. Intrahepatic cholangiocarcinoma: epidemiology, risk factors, diagnosis and surgical management. Cancer Lett. 2015;09:008

21. Bartella I, Dufour JF. Clinical diagnosis and staging of intrahepatic cholangiocarcinoma. J Gastrointestin Liver Dis. 2015;24:481-9.

22. Saxena A, Chua TC, Sarkar A, Chu F, Morris DL. Clinicopathologic and treatment-related factors influencing recurrence and survival after hepatic resection of intrahepatic cholangiocarcinoma: a 19-year experience from an established australian hepatobiliary unit. J Gastrointest Surg. 2010;14:1128-38.

\section{Submit your next manuscript to BioMed Central and we will help you at every step:}

- We accept pre-submission inquiries

- Our selector tool helps you to find the most relevant journal

- We provide round the clock customer support

- Convenient online submission

- Thorough peer review

- Inclusion in PubMed and all major indexing services

- Maximum visibility for your research

Submit your manuscript at www.biomedcentral.com/submit
Biomed Central 